\title{
Residential mobility and the spatial dispersion of personal networks: Effects on social support
}

\author{
Gil Viry ${ }^{\mathrm{a}, \mathrm{b}, *}$ \\ a Department of Sociology, University of Geneva, Uni Mail, 40 Bd du Pont d'Arve, 1211 Genève 4, Switzerland \\ ${ }^{\mathrm{b}}$ Laboratory of Urban Sociology (LaSUR), Swiss Federal Institute of Technology [EPFL], Station 16, 1015 Lausanne, Switzerland
}

\section{A R T I C L E I N F O}

\section{Keywords:}

Personal network analysis

Geographical distance

Residential mobility

Social support

Spatial mobility

Network spatial dispersion

\begin{abstract}
A B S T R A C T
Using a representative national sample of personal networks, this article explores how the spatial dispersion of networks, residential mobility and social support are linked. Three issues will be addressed here. Firstly, how is the spatial dispersion of personal networks related to individuals' social characteristics, network composition and residential mobility? Secondly, how do the spatial dispersion of networks, residential mobility and their combined effect influence the number and (thirdly) the structure of emotional support ties? Results showed that the extent of the support was affected neither by the geographical distribution of the networks nor by residential mobility. Living far from one's birthplace, however, exerted two distinct, and opposite effects on the support network structure. On the one hand, mobility led to high spatial dispersion of personal contacts, which in turn favored a sparsely knit network centered around the mobile individual. On the other hand, by controlling for the effect of distance between the contacts, we found that individuals that cited long-distance ties tended to be part of more transitive support networks than those that cited local ties. We interpreted the latter effect as evidence that transitive ties may survive greater spatial distances than intransitive ones. These findings are discussed in view of spatial mobility and social network research.
\end{abstract}

(c) 2011 Elsevier B.V. All rights reserved.

\section{Introduction}

The ever-increasing need to be spatially mobile - requisite of highly advanced societies - challenges people to find new ways of developing social ties. Less integrated within the local community than sedentary individuals, mobile individuals have the challenge of maintaining their own social ties in a broader spatial range. In this regard, spatial mobility has an ambivalent nature. On the one hand, the spatial dispersion of friends and family is seen as an obstacle to the building of social ties, as it minimizes opportunities for sharing lasting, intimate relationships outside of the household. On the other hand, moving increases the possibility of making new contacts with select individuals and joining new groups outside the local community.

Recently, this debate has received considerable attention from both mobility and social network analysts (e.g. Carrasco et al., 2008; Kesselring, 2006; Larsen et al., 2006; Lubbers et al., 2010; Mok et al., 2007, 2010). One of the important issues here is how networks change in size and structure as people move. One hypoth-

\footnotetext{
* Correspondence address: Department of Sociology, University of Geneva, Uni Mail, 40 Bd du Pont d'Arve, 1211 Genève 4, Switzerland. Tel.: +41 2237988 94; fax: +41223798325.

E-mail address: gil.viry@unige.ch
}

esis argues that mobile people belong to networks that, without necessarily being different in size, are fragmented, i.e. structured around mutually disconnected clusters of ties and personal contacts stemming from their mobility trajectory. Their interpersonal ties in several places prevent them from bringing their various social circles together. Moreover, the social networks developed by mobile people far from their place of origin are likely built around potentially new roles and foci (i.e. new people, places, social positions, (national) cultures or group memberships) (Feld, 1981). We can then assume that these social circles remain relatively disconnected from the original network, not only because they are removed from it, but also because they were built in a different social context. Dispersed both geographically and socially, the personal networks of mobile people are therefore more individualized, less overlapping and more sparsely knit than the personal networks of non-mobile people (Larsen et al., 2006; Urry, 2003; Wellman, 2002; Wittel, 2001; see also the definition of "liberated community" by Wellman et al., 1988).

The fragmentation hypothesis is interesting because it suggests a series of important interrelational consequences in a mobile world. To begin, individuals in these fragmented networks are less restricted in terms of their behavior than those in networks, which are characterized by the collective nature of normative control: if a network member fails to conform to the network's norms, everybody knows everybody else well, and all of its members may react 
jointly (Coleman, 1988, 1990; Milardo, 1988). Taking advantage of the greater autonomy, individuals in fragmented networks can take advantage of intersecting social circles (Simmel, 1999), potentially leading to the production of forms of geographical multiple membership. With this relatively new form of social integration - specific to modern societies -, individuals can develop an original identity based on a confluence of physically distant, relatively disconnected influences (see e.g. Fischer, 1975; Kadushin, 1966). Secondly, these individuals can also benefit from their position as compulsory intermediary between their network members (Burt, 1992), meaning they can broker or mediate between people who are not directly linked, using "tertius gaudens" strategies (i.e. exploit those disconnected parties to their benefit). Thirdly, social ties within fragmented networks are more likely to bridge new clusters and, as such, non-redundant, non-local resources (Granovetter, 1973). A fourth consequence, however, is that these individuals are less likely to benefit from collective mutual support. Unlike densely knit networks, where trust, obligations and mutual aid are reinforced by collective constraints and direct links, members of fragmented networks are less apt to coordinate their efforts when it comes to helping other network members. In such cases, the individual cannot benefit from collective solidarity practices and must deal with each tie separately (Wellman and Frank, 2000). Lastly, fragmented networks also hamper communications by reducing the number of information channels and multiplying the number of intermediaries between any two network members (Baker, 1984).

Although social network analysts have long investigated the impact of geographical distance on interpersonal ties (for pioneering work, see i.e. Fischer, 1982; Wellman and Leighton, 1979; Wellman, 1990; Wellman and Wortley, 1990), large-scale surveys linking the geography and structure of social networks and mobility are still limited. Empirical studies have, thus far, largely focused on specific professional categories characterized by a strong propensity for movement (migrants, highly qualified professions, long-distance commuters). As such, a systematic overview of representative data is missing. This article aims to fill this gap by examining the fragmentation hypothesis using survey data on personal networks in Switzerland. We began by assessing the influence of individuals' social characteristics, network composition and residential mobility on the spatial dispersion of networks. We then investigated the effects of this dispersion and of living far from one's birthplace on the number and structure of support ties.

\section{Spatial mobility and the transformation of interpersonal space}

Sociological studies have shown that social ties in highly advanced societies are built and maintained based not only on proximity, but also distance, with increasingly facilitated access to transportation and communication systems (Castells, 2000; Frei and Axhausen, 2007; Hampton and Wellman, 2002; Larsen et al., 2006; Urry, 2007a; Wellman, 1996, 1999). Consequently, the capacity to build and sustain social ties with individuals that are not necessarily in the immediate vicinity becomes crucial in terms of connecting people (i.e. producing social capital) (Larsen et al., 2006; Urry, 2007b; Wellman, 2001). Because occasional physical co-presence and face-to-face contact are nonetheless necessary for maintaining long-distance ties (Cass et al., 2005; Larsen et al., 2006; Urry, 2003), this also means being able to be spatially mobile (Kaufmann, 2002).

The literature shows that this ability is closely linked to abundant resources and high-level positions in the social structure (social status, economic capital, education) (Carrasco et al., 2008; Cass et al., 2005; Kaufmann et al., 2005; Kenyon, 2006; Le Breton, 2005; Urry, 2007b). Studies on freelance journalists (Bonß et al., 2004; Kesselring, 2005), media workers (Wittel, 2001) and transnational architects and engineers (Kennedy, 2004, 2005) have shown that these individuals, though highly mobile in different ways, are able to maintain and develop an extensive social network, due in part to job-related contacts. The interpersonal skills requisite for such careers, especially the ability to use high-speed transportation and communication technologies, allow some individuals to maintain relationships with relatives and friends in their communities of origin. Ties within this "network sociality" (Urry, 2003; Wittel, 2001) are considered particularly individualized and changeable, based less on a shared, common past or background and more on mobile technologies, including cars, planes, mobile phones, email, etc.

Using a random sample of personal networks, Carrasco et al. (2008) showed however that, when compared with individual characteristics, the network structure only slightly explains the distance between network members. Other recent studies have focused on how geographical distance affects frequency of contact and provision of support between network members. As Axhausen and Frei's work (2007) demonstrates, distance still matters, despite the important role of high-speed mobile technologies. Mok et al. (2007, 2010) showed, for instance, that the frequency of face-toface and telephone contact between individuals in a given network steadily decreased at distances of approximately five and 100 miles respectively. Email contact and the provision of social support were, for the most part, not affected by distance (except marginally, with regard to material support).

Many works on migration also stress the importance of longdistance ties between immigrants and their extended families, which serve as emotional, financial and practical support providers (among others: Bonvalet and Maison, 1999; Chamberlain, 1995; Litwak, 1960; Mason, 1999, 2004). There is also some evidence that individuals that frequently relocate invest little time in their local communities and are more likely to maintain close links with their distant families, rather than establish contacts with new neighbors (Collmer, 2002, 2005; Pelizäus-Hoffmeister, 2001; Shklovski, 2007). Carrasco et al. (2008) found evidence that, although recent immigrants tended to have more distant personal contacts in general than non-immigrants, the number dwindled when only those with whom they had interacted face-to-face in the past year were considered. The authors showed that it was the duration of residence in a given city that influenced the geographical concentration of personal contacts. This finding is consistent with longitudinal studies highlighting the strong network reconstruction tendencies of immigrants in a host country; physical relocation favors turnover with regard to personal relationships, especially peripheral ones, rather than increasing or decreasing in the actual number of contacts (Butler et al., 1973; Larner, 1990; Magdol, 2000). Lubbers et al.'s (2010) longitudinal analysis contributed to understanding changes in immigrants' personal networks, which showed stability in terms of composition and structure, despite a high rate of turnover in terms of personal contacts. Nonetheless, they also observed that immigrants' personal networks became more transitive ("my contacts' contacts become my contacts") over time, due both to new ties between their contacts and the acquisition of new contacts through existing ones.

Finally, earlier research showed that residential mobility may also lead to a shift in the composition of personal networks. Scholars have emphasized that vertical family ties (parents and children) are more likely to survive great distances than relationships with friends, collaterals ( siblings, cousins, etc.) and a fortiori weaker relations (neighbors, coworkers, and other acquaintances) (Bonvalet and Maison, 1999; Coenen-Huther et al., 1994; Collmer, 2002, 2005; Grossetti, 2007). This finding can be explained by normative expectations with regard to relatives and the density of connection of kinship systems (Burt, 2000; Carrasco et al., 2008; Wellman, 1990; Wellman and Wortley, 1990). 
Table 1

Number of personal contacts, contacts living abroad and respondents who lived abroad at the age of 14 .

\begin{tabular}{|c|c|c|c|c|c|c|c|c|}
\hline Full sample & $n$ & $\%$ & $\begin{array}{l}\text { Respondents citing at } \\
\text { least } 2 \text { personal } \\
\text { contacts }\end{array}$ & $n$ & $\%$ & $\begin{array}{l}\text { Respondents citing at least } \\
2 \text { personal contacts, none } \\
\text { living abroad }\end{array}$ & $n$ & $\%$ \\
\hline \multicolumn{3}{|c|}{ Number of personal contacts } & \multicolumn{3}{|c|}{ Number of contacts living abroad } & \multicolumn{3}{|c|}{ Number of respondents who lived abroad at the age of 14} \\
\hline None & 127 & 11.8 & None & 541 & 87.3 & & & \\
\hline 1 & 299 & 27.7 & 1 & 60 & 9.7 & No & 473 & 87.4 \\
\hline 2 & 189 & 17.5 & 2 & 14 & 2.3 & Yes & 54 & 10.0 \\
\hline 3 & 218 & 20.2 & 3 & 4 & 0.6 & Missing & 14 & 2.6 \\
\hline 4 & 213 & 19.8 & 4 & 1 & 0.1 & Total & 541 & 100 \\
\hline Missing & 32 & 3.0 & Total & 620 & 100 & & & \\
\hline Total & 1078 & 100 & & & & & & \\
\hline
\end{tabular}

This study addresses the question of how residential mobility and the spatial dispersion of personal networks affect support behavior between network members. First, we expect that mobile individuals on the whole have more long-distance personal relationships than non-mobile people, regardless of social characteristics or network composition. Due to their residential mobility, these individuals build relationships in a broader geographical range. Their ability to use transportation and telecommunications systems allows them to maintain long-distance confidants, especially kin from their networks of origin.

Secondly, although frequency of contact is likely to diminish with distance, we hypothesize that mobile individuals exchange as much support as non-mobile ones within their personal networks. As residential mobility leads to turnover in personal contacts, geographically distant personal ties are expected to be as supportive as local ties, due to the selection effect: only the strongest ties would be kept despite distance, whereas weaker ones would be replaced with local relationships over time.

Thirdly, we expect less support between the personal contacts of mobile people than of non-mobile ones, thus leading to fragmented personal networks. Their interpersonal ties in several places and around different roles would prevent them from putting their personal contacts in touch with one another.

\section{Data and measures}

The $2005 \mathrm{MOSAiCH}^{1}$ survey included the Swiss portion of the International Social Survey Program's (ISSP) annual survey. 1,078 persons living in Switzerland aged 18 years old and older were randomly selected from the Swiss telephone directory (response rate $=50.1 \%$ ) and interviewed face-to-face based on a standardized questionnaire. The Kish method (see Kish, 1965) was used to select respondents among eligible household members. Relative to the Swiss population as a whole, individuals living alone or in twoperson households were overrepresented. Using the 1985/2004 General Social Survey (GSS) design (Bailey and Marsden, 1999; Burt, 1984), respondents were asked about their social networks based on the following question:

From time to time, most people discuss important matters with other people. Looking back over the past six months, who are the people with whom you discussed matters that are important to you (work, family, politics, etc.)? Just tell me their first names or initials. IF LESS THAN 4 NAMES MENTIONED, PROBE: Anyone else?

Respondents could name up to four discussion partners. About $12 \%$ of the original sample did not cite any personal contacts in their network; about $28 \%$ of the original sample cited only one (see Table 1). These findings are consistent with the level of social isola-

\footnotetext{
1 Sociological Measures and Observation of Attitudes in Switzerland. This study was funded by the Swiss National Science Foundation and conducted by the Swiss Information and Data Archive Service for the Social Sciences (SIDOS).
}

tion observed in the recent study of McPherson et al. (2006), using the same "important matters" name generator. In this study, $44 \%$ of the U.S. population cited either no one or only one discussion partner. Although most people belong to rather extensive personal networks, the core of people's discussion networks centers around a small percentage of people's emotionally close, reliable ties. In this respect, studying core networks is pivotal to understanding their influence on people's behavior and resources in their everyday lives.

Only respondents who cited at least two discussion partners ( $n=620$ ) were retained, in order to measure the relationship structure in networks of size three or more. Information regarding the exact residential location of the respondents at the age of 14 or the exact residential location of the contacts at the time of the interview was not included in the survey data when the location was outside Switzerland. To have detailed information about the respondents' residential mobility and the spatial dispersion of their networks, respondents who lived abroad at the age of 14 ( $n=188$ of the original sample) or respondents who mentioned one or more foreign contacts ( $n=91$ of the original sample) were thus eliminated from the analyses. After listwise deletion, data were composed of a final sample of 473 individuals for the present study (see Table 1).

Differences in the distribution of respondents between the full representative sample and the analytical sample with regard to socio-demographic characteristics are shown in Appendix A. A chisquare test showed no significant differences between the two samples on category scores. Compared to the full sample, we nevertheless observed that older respondents and those living in periurban areas were somewhat underrepresented because they were more likely to cite either no or only one personal contact. The proportion of respondents with the lowest level of education and a low income was also lower in the final sample because these individuals cited less than two discussion partners and were more likely to having grown up abroad. Finally, the proportion of those living alone and, to a lesser extent, those with university degrees was lower in the final sample as well, because they were more likely to cite one or more contacts living abroad.

\subsection{Number and structure of emotional support ties}

Emotional support between network members was measured by asking respondents who supports who within the network. As in other cognitive network studies (Krackhardt, 1987), respondents not only estimated the support exchanged with personal contacts but also the support exchanged between contacts, based on the following questions:

Of these people, who gives you emotional or moral support through everyday difficulties, like when you are feeling a bit down or have had a hard day? And who, including yourself, gives emotional support to [first person mentioned]?" etc.

Five network indices were applied in order to investigate the number and structure of support ties. These measurements 
Table 2

Descriptive statistics of network indices before dichotomization $(n=473)$.

\begin{tabular}{|c|c|c|c|c|c|c|c|c|}
\hline & Mean & Median & SD & Range & Kurtosis & Skewness & Shapiro-Wilk & Jarque-Bera \\
\hline Number of ties received & 2.30 & 2 & 1.09 & $0-4$ & -1.02 & 0.12 & $0.89^{* *}$ & $22.44^{* *}$ \\
\hline Number of ties given & 2.59 & 3 & 1.06 & $0-4$ & -0.33 & -0.54 & $0.89^{* *}$ & $14.41^{* *}$ \\
\hline$\%$ of ties received & 76.99 & 100 & 29.97 & $0-100$ & -0.85 & -0.80 & $0.74^{* *}$ & $65.00^{* *}$ \\
\hline$\%$ of ties given & 86.01 & 100 & 25.93 & $0-100$ & 2.31 & -1.80 & $0.60^{* *}$ & $352.74^{* *}$ \\
\hline Betweenness centrality (\%) & 39.44 & 16.67 & 41.79 & $0-100$ & -1.56 & 0.41 & $0.78^{* *}$ & $61.28^{* *}$ \\
\hline Network density (\%) & 61.28 & 60 & 24.57 & $0-100$ & -0.78 & 0.02 & $0.96^{* *}$ & $12.65^{* *}$ \\
\hline Network transitivity (\%) & 53.56 & 60 & 39.79 & $0-100$ & -1.53 & -0.26 & $0.84^{* *}$ & $51.56^{* *}$ \\
\hline
\end{tabular}

** $p<.01$.

were calculated using Statnet 2 in R environment software tools (Handcock et al., 2003).

- The number of support ties received or provided by respondents within their personal network indicates the number of personal contacts perceived as support providers and support receivers respectively. About the same percentage of respondents named one, two or three support providers or two or three support receivers, so that scores were platykurtically distributed. The Shapiro-Wilk test for medium-sized samples (Royston, 1995) and the Jarque-Bera test, based on the kurtosis and skewness coefficients (under R) confirm the non-normal shape of the distributions (see Table 2). Therefore, the variable was dichotomized into many (3-4) and few (0-2) support ties.

- The proportion of support ties received or given by the respondents within their personal network was also calculated as the proportion of support providers and support receivers among personal contacts respectively. This second network index captures respondents' ability to activate their personal contacts for support. Because a large number of respondents said they exchanged support with all their contacts (about 60\% of the sample for support received by respondents and about $70 \%$ for support given), the variable was skewly distributed. Moreover, small variability in the respondents' network size resulted in a limited number of modalities, so that proportion scores were not normally distributed (see Table 2 ). The variables were therefore dichotomized, with 1 representing 100\% (all contacts activated) and 0 representing a lower percentage.

Network fragmentation was measured based on three indicators:

- Respondents' betweenness centrality measures the proportion of shortest paths (geodesics) between pairs of personal contacts that include the respondent. The support network here was symmetrized by replacing each unilateral or bidirectional relationship with an undirected one. Betweenness centrality captures the extent to which respondents play the role of compulsory intermediary between personal contacts and are instrumental in facilitating the spread of emotional support between them, regardless of the direction of ties. Because extreme values were overrepresented (about $42 \%$ of respondents had a centrality of 0 , and $23 \%$ had a centrality of $100 \%$ ), the variable was recoded at the median into weak versus strong betweenness centrality (see Table 2).

- Density measures the ratio of the number of support ties actually present in the network to the maximum possible number of ties that could be present if the network was complete (directed ties). Density evaluates the support network's degree of cohesion. Because quite a large number of respondents were part of a complete network (13\% of the sample), scores were not normally distributed and the variable was dichotomized at the median into weak versus high density (see Table 2).
- Transitivity measures the proportion of possible ordered triads, obeying the (weak) transitivity condition (i.e. if $a \rightarrow b$ and $b \rightarrow c$, then $\mathrm{a} \rightarrow \mathrm{c}$ ) (out of those potentially intransitive). Transitivity captures the extent to which patterns of support ties follow the logic that "If I support someone who supports someone else, I will also support this other person". This network index measures the degree of closure for all triads in the personal support network. Because extreme values were more common (about $30 \%$ of the networks had transitivity of 0 , and $23 \%$ had transitivity of $100 \%$ ), the variable was likewise dichotomized at the median into weak versus strong transitivity (see Table 2 ).

Based on the aforementioned thresholds, fragmented networks thus correspond to low-density and low-transitivity networks, in which the respondent is highly central. Core network fragmentation does not capture here the degree of disconnectedness between whole clusters of ties, but rather between that of highly influential contacts. Because network indices were dichotomized, the fragmentation hypothesis tested here postulates that an increase in the residential mobility increases the probability of having a fragmented network. The hypothesis is not the greater the residential mobility, the more fragmented the network. A recodification into three-fold scales of network structure indices (lowest score/in-between/highest score) was also tested. Results based on dichotomized, trichotomized and non-recoded variables were identical (see below).

\subsection{Network spatial dispersion and residential mobility}

Geographically speaking, respondents were asked about their current residential location and where they lived at age 14 (municipalities). This same information was then collected for each personal contact. Because this residential location was only collected when the respondent or the contact lived within the country, respondents who lived abroad at the age of 14 or respondents who mentioned one or more foreign contacts were not included in the analyses (see above). Based on the responses, three indicators of geographical distance (in kilometers) were computed using routing software modeling the Swiss road network:

- Averaging the distance between the respondent's residential location and that each of their personal contacts and distance between the residential locations of his/her personal contacts captured the network's spatial dispersion based on two factors. The first (average distance respondent-contacts; $M=21.6 \mathrm{~km}, \mathrm{SD}=33.3 \mathrm{~km}$ ) was relative to the relationship between the respondent and each of his/her personal contacts; the second (average distance between contacts; $M=27.9 \mathrm{~km}, \mathrm{SD}=38.0 \mathrm{~km}$ ) was relative to the relationships between personal contacts only.

- The distance between respondents' current residential location and their residential location at age 14 measures respondents' earlier residential mobility $(M=32.0 \mathrm{~km}, \mathrm{SD}=53.7 \mathrm{~km})$. Although it does not allow us to capture variations in residential location over time, it has the advantage of measuring how far respondents live from 


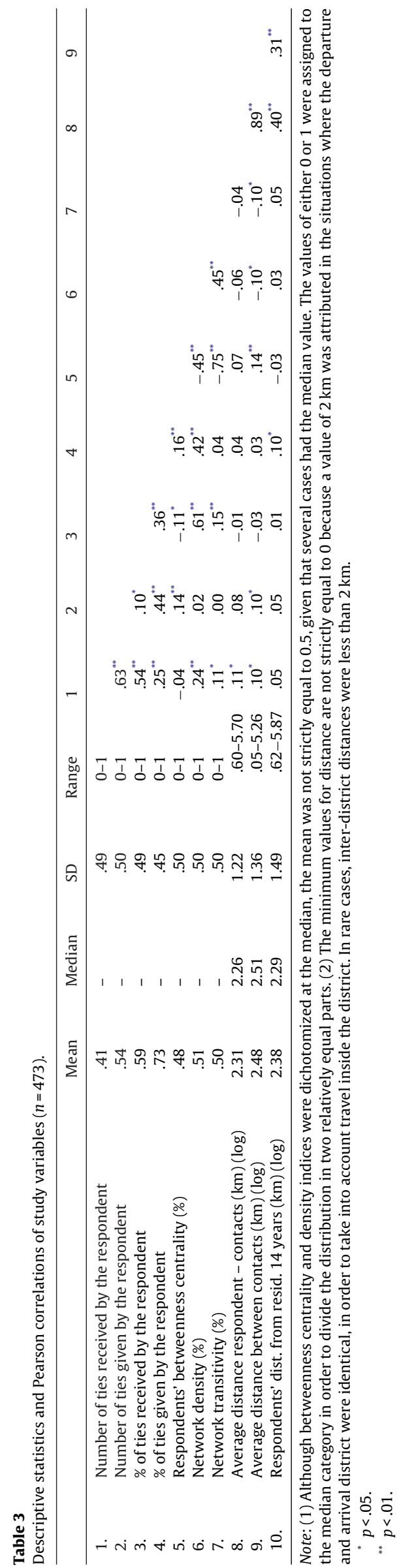

their network of origin (kinship, childhood friends). Regardless of the number and scale of respondents' moves during adulthood, their current distance from their network of origin is relevant for studying the effects of relocation on the spatial and relational reshaping of networks, compared to individuals who still lived in the area they grew up in.

The natural logarithm of these distances was used to reduce the degree of nonlinearity and weight down long distances (assuming that the effect of distance is relatively stable from a certain distance threshold). Descriptive statistics and correlation coefficients between the variables included in the study are shown in Table 3.

\subsection{Control variables}

Three types of factors that could potentially have a mediating effect between residential mobility, network spatial dispersion and the provision of support were considered: respondents' sociodemographical characteristics, how long the network members had known one another and network composition. For the first category, dummy variables were created to control for sex, age, education, household income, residential situation and presence of a partner or children (see Appendix A). Only information from respondents about their household income was missing $(n=65)$. A multiple linear regression model was used to impute missing values based on respondents' work orientation (meaning of work, importance of a good salary), age, and gender, as well as work status (part-time or full-time employment), activity sector, managerial position and level of education of respondents and their partners. Duration of the contacts relationship was measured as a continuous variable, based on the average number of years respondents had known their network members ( $M=25$ years, $\mathrm{SD}=12$ years). Finally, network composition was measured by asking respondents the nature of their relationship (spouse, sibling, friend, etc.) with each of their personal contacts. Using this information, we built homogeneous groupings based on an ascending hierarchical cluster analysis, using Ward's method and squared Euclidean distances (under SPSS) (Aldenderfer and Blashfield, 1984; Everitt, 1993; Lebart et al., 1997). This method has already been used to construct typologies of network composition (see Rapkin and Luke, 1993; Widmer, 2006). Instead of dividing the observations into a predetermined number of clusters in a single step, the hierarchical procedure aggregates the two closest networks, or clusters of networks, step by step, depending on the nature of the relationships with the respondent. A cluster solution is determined by stopping the aggregation procedure at one point. For the present analysis, a series of solutions was examined and the final six-category typology made based on empirical criteria (for purposes of clarity, parsimony and homogeneity). The interpretation of clusters was based on a comparison of the average number of citations for each type of relationship across clusters (see Appendix B). In the four categories "family of procreation" (18\%), "friendship" (17\%), "family of orientation" (10\%) and "professional” (9\%), respondents' networks were characterized by the overrepresentation of children, friends, parents and colleagues respectively. The two last categories were composed of networks marked by a combination of types of relationship. Respondents in the "family-friends" category (27\% of the sample) distinguished themselves from the other types by mentioning both one/several family members outside of the nuclear family (siblings, cousins, aunt, etc.) and friends, but not children. In the "family-work" network type (22\%), respondents predominantly cited family members, particularly children and siblings, and sometimes colleagues, but not friends (see Appendix B). 
Table 4

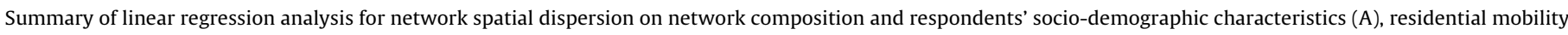
(B), and both (C) (standardized coefficients; $n=473$ ).

\begin{tabular}{|c|c|c|c|c|c|c|c|}
\hline & \multirow[t]{2}{*}{ Dist. from resid. at age $14(\mathrm{log})$} & \multicolumn{3}{|c|}{ Avg. dist. Resp. - Contacts (log) } & \multicolumn{3}{|c|}{ Avg. dist. betw. Contacts (log) } \\
\hline & & A & B & C & A & B & $\mathrm{C}$ \\
\hline \multicolumn{8}{|l|}{ Residential mobility } \\
\hline Dist. from residence at age $14(\log )$ & & & $.40^{* *}$ & $.39^{* *}$ & & $.31^{* *}$ & $.29^{* *}$ \\
\hline \multicolumn{8}{|l|}{ Network composition } \\
\hline Family-friends & $-.10^{*}$ & .02 & & .06 & .07 & & .10 \\
\hline Family-work & - & - & & - & - & & - \\
\hline Family of procreation & -.04 & .03 & & .05 & .05 & & .06 \\
\hline Friendship & -.01 & $.11^{*}$ & & $.12^{*}$ & $.12^{*}$ & & $.13^{*}$ \\
\hline Family of orientation & -.02 & .02 & & .03 & -.02 & & -.01 \\
\hline Professional & -.01 & .00 & & .00 & .00 & & .01 \\
\hline \multicolumn{8}{|l|}{ Sex } \\
\hline Female & $.14^{* *}$ & -.04 & & $-.09^{*}$ & -.03 & & -.07 \\
\hline \multicolumn{8}{|l|}{ Age } \\
\hline $18-34$ & -.03 & .03 & & .05 & .00 & & .01 \\
\hline $35-50$ & - & - & & - & - & & - \\
\hline $51-65$ & $.13^{*}$ & 1.16 & & .02 & .06 & & .02 \\
\hline $66-$ & .02 & -.02 & & -.03 & -.02 & & -.02 \\
\hline \multicolumn{8}{|l|}{ Living arrangement } \\
\hline Alone & -.02 & $.19^{* *}$ & & $.19^{* *}$ & .11 & & .11 \\
\hline With partner without child & -.08 & .06 & & .09 & .08 & & .11 \\
\hline Without partner with child & -.06 & -.02 & & .00 & .00 & & .01 \\
\hline With partner and child & - & - & & - & - & & - \\
\hline Others & $-.19^{* *}$ & -.10 & & -.03 & -.06 & & -.01 \\
\hline \multicolumn{8}{|l|}{ Education } \\
\hline Basic education & - & - & & - & - & & - \\
\hline Apprenticeship & -.01 & .02 & & .02 & .13 & & .13 \\
\hline Vocational school & .02 & .05 & & .04 & .08 & & .08 \\
\hline Advanced vocational school & .11 & .11 & & .07 & $.21^{* *}$ & & $.18^{* *}$ \\
\hline University & .04 & .09 & & .08 & $.17^{* *}$ & & $.16^{* *}$ \\
\hline \multicolumn{8}{|l|}{ Household income } \\
\hline Low & -.01 & -.02 & & -.02 & .00 & & .00 \\
\hline Middle & - & - & & - & - & & - \\
\hline High & .02 & .01 & & .01 & .03 & & .02 \\
\hline \multicolumn{8}{|l|}{ Residential context } \\
\hline Periphery area & -.09 & .10 & & $.14^{* *}$ & .07 & & .10 \\
\hline Periurban area & $-.11^{*}$ & $-.10^{*}$ & & -.06 & $-.10^{*}$ & & -.07 \\
\hline Suburban area & - & - & & - & - & & - \\
\hline Small urban center & $-.11^{*}$ & .02 & & .06 & -.02 & & .01 \\
\hline Medium-size urban center & .02 & .05 & & .04 & .05 & & .05 \\
\hline Large urban center & .01 & $.13^{* *}$ & & $.13^{* *}$ & $.13^{* *}$ & & $.13^{* *}$ \\
\hline$D f$ & 24 & 24 & 1 & 25 & 24 & 1 & 25 \\
\hline$R^{2}$ & $.12^{* *}$ & $.12^{* *}$ & $.16^{* *}$ & $.25^{* *}$ & $.11^{* *}$ & $.10^{* *}$ & $.18^{* *}$ \\
\hline$\Delta R^{2}$ & & & & $.09^{* *}$ & & & $.08^{* *}$ \\
\hline
\end{tabular}

${ }^{*} p<.05$.

** $p<.01$.

\section{Results}

\subsection{The impact of residential mobility on network spatial} dispersion

A first linear regression was run to estimate how people's social characteristics and network composition related to earlier residential mobility (Table 4). Individuals who lived far from their area of residence at age 14 were more likely women and people aged 51-65, compared to those aged 35-50, who constituted the reference category. Conversely, people living in periurban areas and small urban centers, as well as those living in other living arrangements (many of them with parents), lived closer to their area of residence at age 14 than people living in suburban contexts and with a partner and child respectively. Finally, people who belonged to networks of both family and friends lived closer to their area of residence at age 14 than people that cited mainly family members and sometimes colleagues.

To estimate how people's social characteristics, network composition and residential mobility impact the spatial dispersion of their networks, a set of linear regressions was run (Table 4). In models A, the impact of the network composition and respondents' socio-demographic characteristics were estimated. In models B, the impact of respondents' residential mobility was assessed. In models $\mathrm{C}$, network composition, socio-demographic characteristics and residential mobility were considered simultaneously.

Models A showed that people embedded in friendship networks were significantly more likely to live farther from their personal contacts, and that those contacts tended to live farther from one another than individuals who cited family members and sometimes colleagues, which constituted the reference category. The same was true for individuals living in large urban centers, compared to those living in suburban contexts. Furthermore, people who lived alone tended to live further from their personal contacts than individuals who lived with a partner and child(ren), whereas highly skilled individuals were more likely to mention widely dispersed personal contacts. Conversely, individuals living in periurban areas were more likely to have a localized network, compared to those living in suburban contexts. Models B confirmed that residential mobility is a factor in rebuilding social ties on a larger scale: the further an individual lived from his/her current residence at the age of 14, the further his/her contacts lived from one another and from him/her. Models $C$ demonstrated that the previous effects remained unchanged when all variables were included. Only the 
Table 5

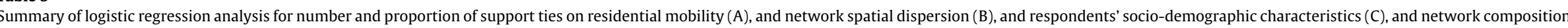
(D) (Odds Ratios; $n=473$ ).

\begin{tabular}{|c|c|c|c|c|c|c|c|c|c|c|c|c|c|c|c|c|}
\hline & \multicolumn{4}{|c|}{ \# of support providers } & \multicolumn{4}{|c|}{ \# of support receivers } & \multicolumn{4}{|c|}{ Proportion of support providers } & \multicolumn{4}{|c|}{ Proportion of support receivers } \\
\hline & A & B & c & D & A & B & $\mathrm{C}$ & D & A & B & $\mathrm{C}$ & D & A & B & c & $\mathrm{D}$ \\
\hline \multicolumn{17}{|l|}{ Residential mobility } \\
\hline Dist. from resid. at age $14(\log )$ & 1.07 & 1.01 & .96 & .98 & 1.06 & 1.04 & 1.00 & 1.03 & 1.02 & 1.02 & .98 & 1.00 & $1.17^{*}$ & $1.17^{*}$ & 1.16 & $1.21^{*}$ \\
\hline \multicolumn{17}{|l|}{ Network spatial dispersion } \\
\hline Avg. dist. resp. - contacts (log) & & 1.16 & 1.18 & 1.14 & & .90 & .83 & .81 & & 1.15 & 1.27 & 1.26 & & .97 & .95 & .99 \\
\hline Avg. dist. betw. contacts (log) & & 1.03 & .99 & .98 & & 1.24 & 1.30 & 1.27 & & .85 & .74 & .73 & & 1.03 & 1.06 & 1.00 \\
\hline \multicolumn{17}{|l|}{ Network acquaintance duration } \\
\hline Avg. \# of years of acquaintance & & & 1.01 & 1.02 & & & 1.00 & 1.02 & & & 1.02 & $1.03^{*}$ & & & 1.01 & 1.02 \\
\hline \multicolumn{17}{|l|}{ Network composition } \\
\hline Family-friends & & & & 1.78 & & & & 1.61 & & & & 1.77 & & & & 1.71 \\
\hline Family-work & & & & - & & & & - & & & & - & & & & - \\
\hline Family of procreation & & & & $6.15^{* *}$ & & & & $9.54^{* *}$ & & & & 1.23 & & & & 1.12 \\
\hline Friendship & & & & $2.27^{*}$ & & & & $4.39^{* *}$ & & & & $2.08^{*}$ & & & & 1.50 \\
\hline Family of orientation & & & & $4.37^{* *}$ & & & & .93 & & & & 1.50 & & & & $.36^{*}$ \\
\hline Professional & & & & $2.51^{* *}$ & & & & 2.06 & & & & 1.38 & & & & .76 \\
\hline \multicolumn{17}{|l|}{ Sex } \\
\hline Female & & & 1.38 & 1.23 & & & 1.28 & 1.10 & & & $1.50^{*}$ & 1.43 & & & 1.49 & 1.47 \\
\hline \multicolumn{17}{|l|}{ Age } \\
\hline $18-34$ & & & .96 & 1.10 & & & 1.16 & 1.61 & & & .88 & .88 & & & 1.48 & 1.80 \\
\hline $35-50$ & & & - & - & & & - & - & & & - & - & & & - & - \\
\hline $51-65$ & & & .92 & .87 & & & .86 & .68 & & & .91 & .94 & & & 1.10 & .89 \\
\hline $66-$ & & & .43 & $.28^{* *}$ & & & .61 & $.30^{* * *}$ & & & $.28^{* *}$ & $.27^{* *}$ & & & .51 & $.38^{*}$ \\
\hline \multicolumn{17}{|l|}{ Living arrangement } \\
\hline Alone & & & .97 & .86 & & & .93 & .77 & & & 1.13 & 1.03 & & & .92 & .81 \\
\hline With partner without child & & & $.48^{*}$ & $.41^{* *}$ & & & .63 & $.50^{*}$ & & & .91 & .86 & & & .85 & .72 \\
\hline Without partner with child & & & 1.15 & .99 & & & 1.48 & 1.17 & & & 2.85 & 3.16 & & & 1.52 & 1.42 \\
\hline With partner and child & & & - & - & & & - & - & & & - & - & & & - & - \\
\hline Others & & & .51 & .49 & & & $.37^{*}$ & $.33^{* *}$ & & & 1.25 & 1.16 & & & .70 & .59 \\
\hline \multicolumn{17}{|l|}{ Education } \\
\hline Basic education & & & - & - & & & - & - & & & - & - & & & - & - \\
\hline Apprenticeship & & & 1.39 & 1.60 & & & 1.24 & 1.63 & & & 1.20 & 1.19 & & & .62 & .65 \\
\hline Vocational school & & & 1.01 & 1.33 & & & 1.82 & $2.93^{*}$ & & & .72 & .75 & & & .38 & $.36^{*}$ \\
\hline Advanced vocational school & & & 1.45 & 1.68 & & & 1.90 & $2.61^{*}$ & & & 1.29 & 1.30 & & & .92 & .98 \\
\hline University & & & 2.00 & 2.47 & & & .36 & 2.22 & & & 2.13 & 1.99 & & & .59 & .57 \\
\hline \multicolumn{17}{|l|}{ Household income } \\
\hline Low & & & 1.12 & 1.11 & & & .89 & .88 & & & 1.25 & 1.22 & & & .74 & 69 \\
\hline Middle & & & - & - & & & - & - & & & - & - & & & - & - \\
\hline High & & & $2.27^{* *}$ & $1.99^{* *}$ & & & .98 & .82 & & & $2.04^{* *}$ & $1.98^{* *}$ & & & 1.28 & 1.37 \\
\hline \multicolumn{17}{|l|}{ Residential context } \\
\hline Periphery area & & & 1.22 & 1.33 & & & 1.28 & 1.48 & & & .94 & 1.00 & & & 1.43 & 1.64 \\
\hline Periurban area & & & .57 & .52 & & & .70 & .58 & & & .76 & .79 & & & 1.36 & 1.35 \\
\hline Suburban area & & & - & - & & & - & - & & & - & - & & & - & - \\
\hline Small urban center & & & .87 & .89 & & & 1.85 & 1.86 & & & $.40^{*}$ & $.42^{*}$ & & & 1.10 & 1.26 \\
\hline Medium-sized urban center & & & 1.17 & 1.04 & & & 1.35 & 1.24 & & & .87 & .91 & & & 1.79 & 2.09 \\
\hline Large urban center & & & $2.98^{* *}$ & $3.25^{* *}$ & & & 1.53 & 1.54 & & & $3.26^{* *}$ & $3.50^{* *}$ & & & .98 & 1.04 \\
\hline$D f$ & 1 & 3 & 23 & 28 & 1 & 3 & 23 & 28 & 1 & 3 & 23 & 28 & 1 & 3 & 23 & 28 \\
\hline $\mathrm{Chi}^{2}$ & 1.16 & 5.71 & $56.53^{* *}$ & $90.53^{* *}$ & .96 & 5.02 & $36.27^{*}$ & $90.58^{* *}$ & .06 & 1.27 & $51.73^{* *}$ & $57.26^{* *}$ & $4.82^{*}$ & 4.85 & 27.75 & $42.50^{*}$ \\
\hline$\Delta \mathrm{Chi}^{2}$ & & 4.55 & $50.82^{* *}$ & $34.00^{* *}$ & & 4.06 & $31.25^{*}$ & $54.31^{* *}$ & & 1.21 & $50.46^{* *}$ & 5.53 & & .03 & 22.90 & $14.75^{*}$ \\
\hline
\end{tabular}


Table 6

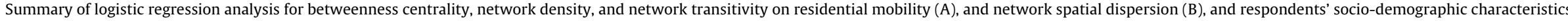
(C), and network composition (D) (Odds Ratios; $n=473$ ).

\begin{tabular}{|c|c|c|c|c|c|c|c|c|c|c|c|c|c|}
\hline & \multicolumn{4}{|c|}{ Betweenness centrality } & \multicolumn{4}{|c|}{ Density } & \multicolumn{4}{|c|}{ Transitivity } & \\
\hline & A & B & C & $\mathrm{D}$ & A & B & C & $\mathrm{D}$ & A & B & C & $\mathrm{D}$ & \\
\hline \multicolumn{14}{|l|}{ Residential mobility } \\
\hline Dist. from resid. at age $14(\log )$ & .96 & .94 & .87 & .89 & 1.05 & 1.08 & 1.08 & 1.08 & 1.08 & 1.10 & $1.18^{*}$ & 1.15 & \\
\hline \multicolumn{14}{|l|}{ Network spatial dispersion } \\
\hline Avg. dist. resp. - contacts $(\log )$ & & $.59^{*}$ & $.58^{*}$ & $.58^{*}$ & & 1.25 & 1.33 & 1.39 & & 1.40 & 1.49 & $1.53^{*}$ & \\
\hline Avg. dist. betw. contacts (log) & & $1.92^{* *}$ & $2.14^{* *}$ & $2.12^{* *}$ & & $.70^{*}$ & $.64^{* *}$ & $.62^{* *}$ & & $.64^{* *}$ & $.56^{*}$ & $.56^{* *}$ & \\
\hline \multicolumn{14}{|l|}{ Network acquaintance duration } \\
\hline Avg. \# of years of acquaintance & & & $.96 *$ & $.97^{*}$ & & & $1.03^{*}$ & $1.03^{*}$ & & & $1.04^{* *}$ & $1.03^{*}$ & \\
\hline \multicolumn{14}{|l|}{ Network composition } \\
\hline Family-friends & & & & $2.24^{* *}$ & & & & 1.31 & & & & $.45^{* *}$ & \\
\hline Family-work & & & & - & & & & - & & & & - & \\
\hline Family of procreation & & & & .91 & & & & 1.03 & & & & 1.22 & \\
\hline Friendship & & & & $2.19^{*}$ & & & & .71 & & & & $.41^{* *}$ & \\
\hline Family of orientation & & & & 1.39 & & & & .81 & & & & .66 & \\
\hline Professional & & & & 1.41 & & & & 1.31 & & & & 1.25 & \\
\hline Sex & & & & & & & & & & & & & \\
\hline Female & & & $2.22^{* *}$ & $2.15^{* *}$ & & & .99 & 1.01 & & & $.57^{* *}$ & $.60^{*}$ & 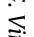 \\
\hline \multicolumn{14}{|l|}{ Age } \\
\hline $18-34$ & & & 1.22 & 1.22 & & & .95 & .96 & & & .92 & .97 & $\bar{n}$ \\
\hline $35-50$ & & & - & - & & & - & - & & & - & - & . \\
\hline $51-65$ & & & 1.22 & 1.28 & & & 1.06 & 1.02 & & & 1.06 & 1.02 & $\frac{2}{z}$ \\
\hline $66-$ & & & 1.02 & 1.00 & & & .55 & .52 & & & .95 & .95 & ई \\
\hline \multicolumn{13}{|l|}{ Living arrangement } & \\
\hline Alone & & & .94 & .85 & & & .77 & .82 & & & .70 & .76 & $\frac{\bar{s}}{\hat{n}}$ \\
\hline With partner without child & & & .92 & .86 & & & .95 & .98 & & & .75 & .80 & x. \\
\hline Without partner with child & & & .36 & .41 & & & 2.78 & 2.98 & & & 2.19 & 1.97 & $\frac{\hat{N}}{\tilde{N}}$ \\
\hline With partner and child & & & - & - & & & - & - & & & - & - & 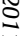 \\
\hline Others & & & 1.00 & .87 & & & .90 & .89 & & & .85 & .96 & \\
\hline \multicolumn{14}{|l|}{ Education } \\
\hline Basic education & & & - & - & & & - & - & & & - & - & 立 \\
\hline Apprenticeship & & & .68 & .64 & & & .82 & .84 & & & 1.83 & $2.02^{*}$ & $\grave{x}$ \\
\hline Vocational school & & & .81 & .76 & & & .68 & .67 & & & .92 & .99 & \\
\hline Advanced vocational school & & & .90 & .87 & & & .87 & .91 & & & 1.88 & 2.10 & \\
\hline University & & & .65 & .53 & & & 1.00 & 1.07 & & & $3.89^{* *}$ & $5.21^{* *}$ & \\
\hline \multicolumn{13}{|l|}{ Household income } & \\
\hline Low & & & 1.25 & 1.20 & & & 1.12 & 1.13 & & & .83 & .86 & \\
\hline Middle & & & - & - & & & - & - & & & - & - & \\
\hline High & & & 1.07 & 1.07 & & & 1.45 & 1.50 & & & .87 & .88 & \\
\hline \multicolumn{13}{|l|}{ Residential context } & \\
\hline Periphery area & & & $.23^{* *}$ & $.58^{*}$ & & & 1.23 & 1.22 & & & $1.93^{* *}$ & $1.75^{*}$ & \\
\hline Periurban area & & & $.44^{*}$ & $.33^{* *}$ & & & 1.34 & 1.45 & & & $2.53^{* *}$ & $2.42^{*}$ & \\
\hline Suburban area & & & - & - & & & - & - & & & - & - & \\
\hline Small urban center & & & .79 & .87 & & & .72 & .73 & & & $2.15^{*}$ & 1.86 & \\
\hline Medium-sized urban center & & & $.30^{* *}$ & $.49^{*}$ & & & 1.46 & 1.50 & & & $2.64^{* *}$ & $2.37^{* *}$ & \\
\hline Large urban center & & & $.54^{*}$ & $.24^{* *}$ & & & $2.44^{*}$ & $2.45^{*}$ & & & $3.04^{* *}$ & $2.82^{* *}$ & \\
\hline$D f$ & 1 & 3 & 23 & 28 & 1 & 3 & 23 & 28 & 1 & 3 & 23 & 28 & \\
\hline $\mathrm{Chi}^{2}$ & .34 & $18.54^{* *}$ & $81.78^{* *}$ & $93.80^{* *}$ & .51 & $8.92^{*}$ & 32.67 & 37.54 & 1.39 & $11.86^{* *}$ & $69.38^{* *}$ & $86.98^{* *}$ & \\
\hline$\Delta \mathrm{Chi}^{2}$ & & $18.20^{* *}$ & $63.24^{* *}$ & $12.02^{* *}$ & & $8.41^{*}$ & 23.75 & 4.87 & & $10.47^{* *}$ & $57.52^{* *}$ & $17.60^{* *}$ & \\
\hline
\end{tabular}


effects of living in a periurban area lost their significance when residential mobility was introduced. This means that people living in periurban areas often lived closer to their personal contacts, and that those contacts lived closer to one another because people living in periurban areas were less mobile than people living in suburban contexts. Moreover, two additional effects proved significant when residential mobility was included in the model. Controlling for residential mobility, individuals living in periphery areas lived farther from their contacts than people living in suburban contexts. Finally, women on the whole lived as close to their personal contacts as men, but further away from their area of residence at age 14. In other words, for a given distance from their area of origin, women lived closer to their personal contacts than men.

\subsection{The two, contrary effects of residential mobility on support network structure}

To estimate how network spatial dispersion and earlier residential mobility affected the provision and structure of emotional support within personal networks, a set of regressions was run using the number and proportion of ties received and given by the respondent, betweenness centrality, density and transitivity as outcomes (Tables 5 and 6). Models A show the effect of earlier residential mobility. In models $B$, the spatial dispersion of the network was included. Control variables were added in models $\mathrm{C}$, and the network composition was included in models D. As dependent variables were dichotomized, binary logistic analyses were appropriate. Alternative models were also tested, however, including ordinal logistic regressions (PLUM procedure of SPSS), with dependent variables recoded into three-fold scales and OLS regressions without recodification. Results were identical in both cases.

As expected, neither the spatial dispersion of networks nor the distance from the area of residence at age 14 significantly affected the number or proportion of support ties received or provided by respondents. Individuals with long-distance personal contacts shared as many support ties as people with localized networks. Only the proportion of support receivers was positively influenced by earlier residential mobility: the further people lived from their area of residence at age 14, the more they supported the persons they mentioned in their network. The proportion of support providers of mobile people, however, did not differ from that observed for non-mobile people. The absence of a significant link between the spatial dispersion of networks and the provision of support could be due to the fact that the number of support ties could vary only between two and four. When the whole sample was used and distance between personal contacts excluded from the analysis (which allowed for retention of people citing only one personal contact), respondents who lived far from their personal contacts were more likely to cite a greater number of persons as support providers and receivers, with or without control variables. There was, however, no significant impact on the proportion of support ties after adding controls (results not reported).

Additionally, it appeared that people aged 66 or more had fewer personal support contacts (absolute and in proportion to the number of persons cited in the network). Conversely, higher-income people and those living in big cities received more support (absolute and in proportion) than middle-income people and those living in suburban contexts respectively. Also, the longer people had known their personal contacts, the higher the proportion of support providers was. Network composition likewise strongly influenced the provision of support. Compared to people that cited mainly family members and sometimes colleagues in their network (reference group), people embedded in a friendship network received more support (absolute and in proportion). Furthermore, people that cited children predominantly claimed giving and receiving more support, due to the fact that they cited more contacts within their network. Lastly, people that cited mainly parents received more support ties in absolute terms, but supported their contacts less proportionally speaking, due to the asymmetrical nature of the parent-child bond.

We likewise had hypothesized that less support was exchanged between the personal contacts of mobile people because they were more distant from one another, compared to the contacts of non-mobile people, thus leading to a fragmented structure. Empirical results show that this expectation should be rejected in favor of a more complex pattern of effects. A significant relationship between geographically dispersed contacts and network fragmentation was indeed observed: the more distant the personal contacts in a network were from one another, the more individuals played the role of intermediary between them, and the less dense and less transitive the support network was (Table 6). However, contrary to expectations, our findings showed that, although people living far from their area of residence at age 14 often had more contacts living far away from one another (Table 4), they were not more likely to be part of fragmented networks. As residentially mobile people were also characterized by a greater distance between them and their contacts, this exerted a contrary effect on the network structure. While controlling for the effects of spatial dispersion of personal contacts and residential mobility, the distance between respondents and their contacts fostered a transitive, weakly centralized support network. Moreover, irrespective of the network's spatial dispersion, earlier residential mobility favored a transitive structure. This effect nonetheless disappeared when network composition was included in the model. Friendship and "family-friends"-type networks were less transitive than "family-work"-type ones, which constituted the reference category. Residentially mobile people had thus more transitive networks than non-mobile ones because they were less likely embedded in networks of the "family-friends"-type (see also Table 4). All these effects likewise held true when network size was included in the regression models (results not reported).

Results of the regressions likewise showed that women and people living in suburban areas were more likely embedded in intransitive, strongly centralized support networks, while individuals with university degrees more often had transitive personal networks compared to those with a basic level of education. Finally, the longer people knew their personal contacts, the less they played the role of intermediary between them and the denser and more transitive their networks were.

\section{Discussion}

This study examined the impact of the spatial dispersion of networks and earlier residential mobility on the provision of emotional support within personal networks. The general hypothesis was that residential mobility fosters personal networks that are geographically spread out and that, in turn, favor a fragmented structure, i.e. sparsely connected, intransitive support networks in which mobile people play the role of compulsory intermediary between their personal contacts. Based on our data, this expectation was confirmed but accounted only in part for the mechanism. We found that earlier residential mobility did foster spatially dispersed personal networks, which in turn favored fragmented networks. But at the same time, the further respondents lived from their place of birth, the more distant they were from their personal contacts and the more transitive and less centralized their support networks were, counteracting for the impact of distance between contacts. Moreover, because residentially mobile people less frequently had networks composed of both friends and family members, their personal networks tended to be more transitive than the networks of sedentary individuals. 
Consistent with previous studies on this topic (Magdol, 2000; Ohnmacht et al., 2008), our research confirmed that individuals with a history of residential mobility tended to have personal networks that were dispersed. The further respondents lived from their area of residence at age 14 , the farther their personal contacts tended to live from one another and the further respondents tended to live from them - a finding which suggests that earlier residential mobility has an enduring influence on the rebuilding of social networks on a larger geographical scale. Presumably less embedded in neighborhood relationships, mobile individuals were more likely to cite important contacts living near a distant place of birth. This finding also suggests that mobility experiences are linked to individuals' skills and resources with regard to the use of highspeed transportation and telecommunications networks, allowing them to maintain long-distance ties and build intimate relationships in several places (Boase et al., 2006; Hampton and Wellman, 2002; Kaufmann, 2002; Larsen et al., 2006). The spatial dispersion of an individual's personal network is the product of a complex phenomenon that combines not only job- and family-related mobility trajectories and attachment to persons or places over the course of an individual's life, but also the strategies and resources he/she uses to maintain strong ties over long-distances (Larsen et al., 2006; Urry, 2007a; Wellman, 2001). Moreover, individuals living alone also tended to have more dispersed networks than those living with partner and children. This finding is coherent with previous studies that show the shrinking and overlapping of friendship networks between partners over the life course (see e.g. Bidart and Lavenu, 2005; Kalmijn, 2003). People in friendship networks also had more geographically scattered personal networks compared to individuals who cited mainly family members and sometimes colleagues. While earlier research shows that friendship ties were less likely to survive great distances than relationships with family members (Bonvalet and Maison, 1999; Coenen-Huther et al., 1994; Grossetti, 2007), the high percentage of people embedded in friendship networks that did not mention a partner might explain this result. Moreover, our findings are consistent with the observations that highly educated people have a greater capacity for maintaining strong, long-distance relationships with family and friends (Bonvalet and Maison, 1999; Rémy and Voyé, 1992), since highly educated people tend to have more dispersed personal contacts than less-educated individuals. Controlling for the effect of residential mobility, the analyses likewise showed that women lived closer to their personal contacts than did men. Overall, however, we found that women lived the same distance from their personal contacts as men, since women also lived further away from their area of residence at age 14 . This result supports the hypothesis that women are more locally rooted than men due to their responsibility for housework and childcare, once the effect of maintaining contact with kin near the birthplace is taken into account (Wellman, 1985; Wellman and Wellman, 1992). The context of respondents' current residential location also significantly influenced the geographical distance between network members. People living in big cities and remote areas belonged to networks that were geographically broader than individuals living on the outskirts of urban centers. In this latter context, large dwellings and being a homeowner, as well as the relatively strong community-building values of people living in suburban and periurban neighborhoods, might explain this finding (Teller, 2009).

Secondly, as highlighted in past research on larger networks (Grossetti, 2007; Larner, 1990; Magdol, 2000), this study upholds the expectation that, in the long term, residential mobility has only a minor impact on the number of strong personal ties. More specifically, the analyses performed in this study showed that the number of support ties was significantly affected neither by the geographical dispersion of personal networks, nor by distance from the place of birth. This outcome is consistent with longitudinal studies that emphasize the importance of turnover in personal relationships (rather than an increase or decrease in the actual number of ties) in the case of residential relocation (Butler et al., 1973; Larner, 1990; Lubbers et al., 2010; Magdol, 2000). Long-distance support relationships were reported as frequently as were local ones, probably because only the strongest, most intimate ties were maintained over distances, whereas weaker ties were eliminated (selection effect). It also suggests that emotionally supportive ties may be maintained via telecommunications and occasional visits (Boase et al., 2006; Larsen et al., 2006). Regardless of the spatial dispersion of the network, analyses nonetheless showed that long-distance relocation had a positive impact on the proportion of support ties given by the respondent; the further he/she lived from his/her residence at the age of 14 , the greater the chance he/she supported the people he/she cited in the network. The proportion of support received by the mobile respondents, however, did not differ from that observed for non-mobile people. This finding can be interpreted as the consequence of recent arrivals' efforts at rebuilding a support network in the new residential location. Earlier studies have shown that recent residential relocation may lead individuals to focus on a small, emotionally intimate group and multiplex ties (good friends and certain family members), rather than maintaining ties with a large number of less-intimate individuals (Bidart and Lavenu, 2005; Collmer, 2002, 2005; Jones, 1973; PelizäusHoffmeister, 2001; Shklovski, 2007). In the years following the move, the individual's support network might be concentrated among a small number of people that he/she is more likely to cite as support receivers than he/she would within a larger network of weaker ties (Granovetter, 1973). This hypothesis must still be confirmed through additional research.

Thirdly, as expected, individuals with personal contacts that were geographically distant from one another were more likely to become the center of a loosely connected, intransitive network, whose contacts supported one another less than contacts within localized networks. The effect of geographical distance could not be eliminated here, so that individuals were integrated in fragmented networks. Personal contacts supported each other less, probably because they did not know one another well and had fewer opportunities to get together. One can also wonder about the extent to which individuals attempt to connect their distant personal contacts with one another or do not, based on their strategies and resources. Due to geographically widespread social embedding, it appeared that individuals were not fully able - or willing - to exert this logic of transitivity, which lies at the heart of social network building (Davis, 1970; Simmel, 1999).

Finally, while residential mobility favored geographically dispersed personal contacts, people living far from their place of birth were not more likely to become part of a fragmented network than those living in the area they grew up in, as being far from one's personal contacts concurrently fostered a transitive and a weakly centralized structure. Controlling for residential mobility and the distance between personal contacts, the further respondents lived from their contacts, the more transitive and less respondent-centered their networks were. As we saw earlier, the provision of support between respondents and their contacts did not significantly differ according to network spatial dispersion. Thus, these differences in transitivity and centrality most likely stem from a difference in the provision of support between contacts. In other words, for a given average distance between personal contacts, the more distant respondents were from them, the more likely the contacts were to support each other. The left- and righthand diagrams in Fig. 1 illustrate two scenarios wherein the spatial dispersion of personal contacts $(\mathrm{C} 1-\mathrm{C} 3)$ is identical. In the righthand diagram, the average distance between the respondent $(R)$ and the contacts is higher than in the left-hand diagram. Our findings suggest that personal contacts (C1 and C2) are more likely 

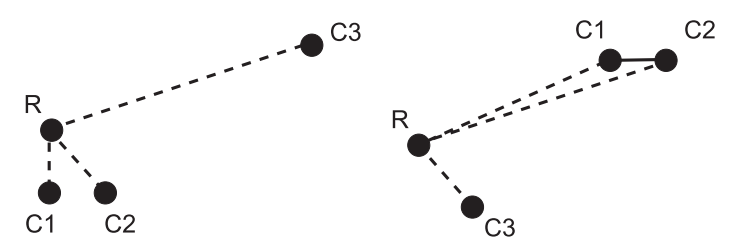

Fig. 1. Illustration of the lower probability of support between two contacts living near the respondent (left), compared to two contacts living far from the respondent (right), for a given average distance between the contacts.

to exchange support when the respondent is distant from them (right-hand diagram) than when the respondent is close (left-hand diagram). This mechanism can be interpreted in two ways. Firstly, transitive ties are more likely to survive greater distances than intransitive ones (Wellman, 1990; Wellman and Wortley, 1990). Indeed, distant ties are more likely to be strong than local ones (see, for example, Fischer, 1982; Grossetti, 2007; Larsen et al., 2006). Because weaker ties are more likely to be part of intransitive triads (Granovetter, 1973), two contacts who do not support one other are more likely to be geographically close to the respondent, given the geographical distance between them. Secondly, having contacts that know and support one another facilitates travel and face-toface meetings, which are necessary to sustain intimate bonds at a distance (Larsen et al., 2006; Urry, 2003). The friction of distance can be partially compensated for by seeing several contacts at the same time.

The fact that residential mobility did not foster fragmented networks can also be explained by a shift in the composition of personal networks. People living far from their area of residence at age 14 had more transitive networks than those living in the area they grew up in because they were less likely to be embedded in networks composed of both family members and friends. This result is consistent with previous findings showing that geographical moves, often coupled with work/married life, lead to an overall decrease in the presence of friends in the network (see e.g. Bidart and Lavenu, 2005). The decrease in the number of friends happens mainly in favor of family members, who develop more transitive ties.

This study addressed some of the dimensions associated with the spatiality of social integration in a mobile world. Several limitations should nonetheless be mentioned. To begin, the data contained only small networks of emotionally close people. Respondents were therefore likely to cite discussion partners for "important matters" as support receivers/providers. This may have contributed to the insignificant findings as regards the association between the provision of support with the respondent and network spatial dispersion. Moreover, the small variability in respondents' network size resulted in the limited number of modalities of the network indices. Accordingly, the network indices could only be evaluated based on threshold values (low vs. high network density, etc.), instead of being measured in a continuous way. It would therefore be interesting to test the fragmentation hypothesis on larger personal networks potentially structured around multiple clusters of ties. In addition, the analyses performed in this study were at the network level. Therefore, it would be helpful to test whether the same mechanisms can be detected at the relationship level. One could, in particular, analyse whether or not long-distance personal contacts are more likely to support one other than geographically close personal contacts, given the geographical distance between them. Additional information about the strength of ties would make it possible to test whether long-distance ties are more transitive than local ones because they are stronger. Thirdly, because of the limitations of the data, it was not possible to include international migration in the analyses, nor some of the potentially important characteristics of mobility practices. Residential mobility was measured with only one item to capture for distance from the network of origin, but did not provide any details regarding different aspects of earlier residential mobility, such as timing, distance and frequency of moves or the length of residence in the current home. Finally, the data were cross-sectional. Future research on the effects of spatial mobility on network structure would benefit from longitudinal data that would help capture changes in the structure of ties in personal networks over the life course and mobility trajectory.

Nevertheless, this study offers new insights into the impact of spatial mobility and geographical distance on support networks, and provide interesting ideas for future research. The coexistence of a fragmented structure, associated with the spatial dispersion of personal contacts, and a transitive structure, linked with a distance-based selection process, revealed that physical distance with friends and family leads to new and complex modes of social integration that cannot be reduced to the pure individualization of social ties.

\section{Acknowledgements}

The author wishes to express his thanks to Eric D. Widmer, Vincent Kaufmann and Eva Nada, as well as anonymous reviewers, for their helpful comments to earlier versions of this article, although they are not necessarily in agreement with the author's point of view. Many thanks also to Dominique Joye, Ivan De Carlo and Gilbert Ritschard for their help in data formatting and statistical analyses, and to Jessica Strelec for her language assistance. This work was supported by the Swiss National Science Foundation (SNSF) (project no. 100015-113693) and the survey was conducted by the Swiss Information and the Data Archive Service for the Social Sciences (SIDOS). Both are also gratefully acknowledged. 
Appendix A.

Distribution of respondents in the full sample and analytical sample (\%).

\begin{tabular}{|c|c|c|}
\hline & $\begin{array}{l}\text { Full sample } \\
(n=1078)\end{array}$ & $\begin{array}{l}\text { Analytical } \\
\text { sample } \\
(n=473)\end{array}$ \\
\hline \multicolumn{3}{|l|}{ Sex } \\
\hline Female & 53.0 & 52.6 \\
\hline \multicolumn{3}{|l|}{ Age } \\
\hline $18-34$ & 21.9 & 26.6 \\
\hline $35-50$ & 30.6 & 33.4 \\
\hline $51-65$ & 26.9 & 24.7 \\
\hline $66-$ & 20.6 & 15.2 \\
\hline \multicolumn{3}{|l|}{ Living arrangement } \\
\hline Alone & 30.5 & 25.4 \\
\hline With partner without child & 29.2 & 31.7 \\
\hline Without partner with child & 3.7 & 3.8 \\
\hline With partner and child & 27.0 & 28.8 \\
\hline Others & 9.6 & 10.4 \\
\hline \multicolumn{3}{|l|}{ Education } \\
\hline Basic education & 17.1 & 12.7 \\
\hline Apprenticeship & 41.3 & 46.1 \\
\hline Vocational school & 8.1 & 7.0 \\
\hline Advanced vocational school & 23.9 & 26.4 \\
\hline University & 9.6 & 7.8 \\
\hline \multicolumn{3}{|l|}{ Household income } \\
\hline Low & 28.7 & 23.0 \\
\hline Middle & 48.2 & 49.3 \\
\hline High & 23.1 & 27.7 \\
\hline \multicolumn{3}{|l|}{ Residential context } \\
\hline Periphery area & 22.4 & 29.0 \\
\hline Periurban area & 16.4 & 11.4 \\
\hline Suburban area & 29.8 & 29.2 \\
\hline Small urban center & 11.0 & 9.1 \\
\hline Medium-size urban center & 11.7 & 12.7 \\
\hline Large urban center & 8.6 & 8.7 \\
\hline \multicolumn{3}{|l|}{ Residential mobility } \\
\hline Distance from residence at age $14(\mathrm{~km})$ (mean) & 31.95 & 34.28 \\
\hline
\end{tabular}

Note: in the case of the full sample, distance from the residence at age 14 was calculated based on the subsample of 882 persons, as respondents who lived abroad at this age were declared missing.

\section{Appendix B.}

Types of network composition (means).

\begin{tabular}{|c|c|c|c|c|c|c|c|c|}
\hline Number of citations & Family-friends & Family-work & $\begin{array}{l}\text { Family of } \\
\text { procreation }\end{array}$ & Friendship & $\begin{array}{l}\text { Family of } \\
\text { orientation }\end{array}$ & Professional & & \\
\hline & I & II & III & IV & $\mathrm{V}$ & VI & Tot & $\mathrm{Eta}^{2}$ \\
\hline Size of cluster (\%) & 27 & 22 & 18 & 17 & 10 & 7 & 100 & \\
\hline$N$ & 128 & 103 & 84 & 80 & 47 & 31 & 473 & \\
\hline Partner & .55 & .69 & .69 & .29 & .70 & .42 & .57 & $.09^{* *}$ \\
\hline \# Parents & .19 & .22 & .07 & .15 & 1.62 & .48 & .33 & $.55^{* *}$ \\
\hline \# Children & .03 & .45 & 1.96 & .00 & .00 & .00 & .45 & $.79^{* *}$ \\
\hline \# Siblings & .39 & .61 & .05 & .10 & .21 & .10 & .29 & $.16^{* *}$ \\
\hline \# Other family ties & .30 & .03 & .21 & .00 & .00 & .00 & .13 & $.11^{* *}$ \\
\hline \# Friends & 1.10 & .04 & .39 & 2.56 & .47 & .13 & .86 & $.74^{* *}$ \\
\hline \# Colleagues & .17 & .32 & .04 & .07 & .09 & 1.94 & .27 & $.56^{* *}$ \\
\hline \# Neighbors & .02 & .08 & .01 & .01 & .00 & .00 & .03 & $.03^{*}$ \\
\hline \# Members of a same assoc. & .02 & .06 & .00 & .00 & .00 & .00 & .02 & .02 \\
\hline \# Prof. counselor (psy., etc.) & .02 & .04 & .01 & .01 & .00 & .03 & .02 & .01 \\
\hline \# Other non-family ties & .00 & .11 & .00 & .06 & .02 & .03 & .04 & $.03^{* *}$ \\
\hline
\end{tabular}

Note: other family members: cousins, uncle, aunt, godparents, parents-in-law.

${ }^{*} p<.05$.

** $p<.01$. 


\section{References}

Aldenderfer, M., Blashfield, R.K., 1984. Cluster Analysis. Sage Publications, Beverly Hills, CA.

Axhausen, K.W., Frei, A., 2007. Contacts in a Shrunken World. Arbeitsbericht Verkehrs-und Raumplanung, vol. 440. IVT, ETH Zürich, Zürich.

Bailey, S., Marsden, P.V., 1999. Interpretation and interview context: examining the General Social Survey name generator using cognitive methods. Social Networks 21, 287-309.

Baker, W., 1984. The social structure of a national securities market. American Journal of Sociology 89, 775-811.

Bidart, C., Lavenu, D., 2005. Evolutions of personal networks and life events. Social Networks 27, 359-376.

Boase, J., Horrigan, J.B., Wellman, B., Rainie, L., 2006. The Strength of Internet Ties. Pew Internet and American Life Project, Washington, DC.

Bonß, W., Kesselring, S., Weiss, A., 2004. Society on the move. Mobilitätspioniere in der zweiten Moderne. In: Beck, U., Lau, C. (Eds.), Entgrenzung und Entscheidung: was ist neu an der Theorie reflexiver Modernisierung. Suhrkamp, Frankfurt am Main, pp. 258-280.

Bonvalet, C., Maison, D., 1999. Famille et entourage: le jeu des proximités. In: Bonvalet, C., Gotman, A., Grafmeyer, Y.(Eds.), La famille et ses proches. L'aménagement des territoires. Ined/PUF, Paris, pp. 83-110.

Burt, R.S., 1984. Network items and the general social survey. Social Networks 6 , 293-339.

Burt, R.S., 1992. Structural Holes: the Social Structure of Competition. Harvard University Press, Cambridge, MA

Burt, R.S., 2000. Decay functions. Social Networks 22, 1-28.

Butler, E.W., McAllister, R.J., Kaiser, E.J., 1973. The effects of voluntary and involuntary residential mobility on females and males. Journal of Marriage and the Family 35, 219-227.

Carrasco, J.-A., Miller, E.J., Wellman, B., 2008. How far and with whom do people socialize? Empirical evidence about the distance between social network members. Transportation Research Record: Journal of the Transportation Research Board 2076, 114-122.

Cass, N., Shove, E., Urry, J., 2005. Social exclusion, mobility and access. The Sociological Review 53, 539-555.

Castells, M., 2000. The Rise of the Network Society. Blackwell, Oxford.

Chamberlain, M., 1995. Family narratives and migration dynamics. Immigrants and Minorities 14, 153-169.

Coenen-Huther, J., Kellerhals, J., Von Allmen, M., 1994. Les réseaux de solidarité dans la famille. Réalités sociales, Lausanne.

Collmer, S., 2002. Heute hier morgen fort - Zur Mobilität des modernen Soldaten In: Kümmel, G., Collmer, S. (Eds.), Europäische Streitkräfte in der Postmoderne. Nomos Verlagsgesellschaft, Baden Baden, pp. 97-115.

Collmer, S., 2005. Soldat, Familie und Mobilität: Neue Trends zur Lösung widersprüchlicher Anforderungen. In: Kümmel, G. (Ed.), Diener zweier Herren: Soldaten zwischen Bundeswehr und Familie. Lang, Frankfurt am Main, pp. 53-77.

Coleman, J., 1988. Social capital and the creation of human capital. American Journal of Sociology 94, 95-121.

Coleman, J., 1990. Foundations of Social Theory. Harvard University Press, Cambridge, MA.

Davis, J.A., 1970. Clustering and hierarchy in interpersonal relations. American Sociological Review 35, 843-851.

Everitt, B.S., 1993. Cluster Analysis. Edward Arnold, New York.

Feld, S.L., 1981. The focused organization of social ties. American Journal of Sociology $86,1015-1035$.

Fischer, C., 1975. Toward a subcultural theory of urbanism. American Journal of Sociology 80, 1319-1341.

Fischer, C., 1982. To Dwell Among Friends. University of California Press, Berkeley.

Frei, A., Axhausen, K.W., 2007. Size and structure of social network geographies Arbeits-berichte Verkehrs-und Raumplanung, vol. 439. IVT, ETH Zürich, Zürich.

Granovetter, M.S., 1973. The strength of weak ties. American Journal of Sociology $78,1360-1380$

Grossetti, M., 2007. Are French networks different? Social Networks 29, 391404.

Hampton, K., Wellman, B., 2002. The not so global village of Netville. In: Wellman, B., Haythornthwaite, C. (Eds.), The Internet in Everyday Life. Blackwell, Oxford, pp. 345-371.

Handcock, M.S., Hunter, D.R., Butts, C.T., Goodreau, S.M., Morris, M., 2003. Statnet: Software tools for the Statistical Modeling of Network Data. http://statnetproject.org.

Jones, S., 1973. Geographic mobility as seen by the wife and mother. Journal of Marriage and the Family 35, 210-218.

Kadushin, C., 1966. The friends and supporters of psychotherapy: on social circles in urban life. American Sociological Review 31, 786-802.

Kalmijn, M., 2003. Shared friendship networks and the life course: an analysis of survey data on married and cohabiting couples. Social Networks 25, 231249.

Kaufmann, V., 2002. Re-thinking Mobility. Ashgate, Aldershot, UK.

Kaufmann, V., Montulet, B., Le Breton, E., 2005. Mobilité et mobilités familiales. Netcom - Networks and Communication Studies 19, 137-139.

Kennedy, P., 2004. Making global society: friendship in networks among transnational professionals in the building design industry. Global Networks 4, 157179.
Kennedy, P., 2005. Joining, constructing and benefiting from the global workplace: transnational professionals in the building-design industry. Sociological Review 53, 172-197.

Kenyon, S., 2006. Reshaping patterns of mobility and exclusion? The impact of virtual mobility upon accessibility, mobility and social exclusion. In: Sheller, M., Urry, J. (Eds.), Mobile Technologies of the City. Routledge, London, pp. 102120.

Kesselring, S., 2005. New mobilities management. Mobility pioneers between first and second modernity. Zeitschrift für Familienforschung, 129143.

Kesselring, S., 2006. Pioneering mobilities: new patterns of movement and motility in a mobile world. Environment and Planning A 38, 269-279.

Kish, L., 1965. Survey Sampling. Wiley, New York.

Krackhardt, D., 1987. Cognitive social structures. Social Networks 9, 109134

Larner, M., 1990. Local residential mobility and its effects on social networks: a cross-cultural comparison. In: Cochran, M., Larner, M., Riley, D., Gunnarsson, L., Henderson, C.R. (Eds.), Extending Families. The Social Networks of Parents and their Children. Cambridge University Press, pp. 205-229.

Larsen, J., Urry, J., Axhausen, K., 2006. Mobilities, Networks, Geographies. Ashgate, Aldershot, UK.

Lebart, L., Morineau, A., Piron, M., 1997. Statistique exploratoire multidimensionnelle. Dunod, Paris.

Le Breton, E., 2005. Bouger pour s'en sortir. Mobilité quotidienne et intégration sociale. Armand Colin, Paris.

Litwak, E., 1960. Geographic mobility and extended family cohesion. American Sociological Review 25, 385-394.

Lubbers, M.J., Molina, J.L., Lerner, J., Brandes, U., Avila, J., McCarty, C., 2010. Longitudinal analysis of personal networks. The case of Argentinean migrants in Spain. Social Networks 32, 91-104.

Magdol, L., 2000. The people you know: the impact of residential mobility on mothers' social network ties. Journal of Social and Personal Relationships 17, 183204.

Mason, J., 1999. Living away from relatives: kinship and geographical reasoning. In: McRae, S. (Ed.), Changing Britain: Families and Households in the 1990. Oxford University Press, Oxford, UK.

Mason, J., 2004. Managing kinship over long distances: the significance of the visit Social Policy and Society 3, 421-429.

McPherson, M., Smith-Lovin, L., Brashears, M.E., 2006. Social isolation in America: changes in core discussion networks over two decades. American Sociological Review 71, 353-375.

Milardo, R.M., 1988. Families and Social Networks. Sage, NewBury Park.

Mok, D., Wellman, B., Basu, R., 2007. Did distance matter before the Internet? Interpersonal contact and support in the 1970. Social Networks 29, 430-461.

Mok, D., Wellman, B., Carrasco, J.-A., 2010. Does distance still matter in the age of the Internet? Urban Studies 47, 2747-2783.

Ohnmacht, T., Frei, A., Axhausen, K.W., 2008. Mobility biography and network geography: whose social relations are spatially dispersed? Swiss Journal of Sociology 34, 131-164.

Pelizäus-Hoffmeister, H., 2001. Mobilität: Chance oder Risiko für soziale Beziehungen? Soziale Netzwerke unter den Bedingungen räumlicher Mobilität - das Beispiel freie JournalistInnen. Leske \& Budrich, Opladen.

Rapkin, B.D., Luke, D.A., 1993. Cluster analysis in community research: epistemology and practice. American Journal of Community Research 21, 247277.

Rémy, J., Voyé, L., 1992. La ville: vers une nouvelle définition? L'Harmattan, Paris.

Royston, P., 1995. Remark AS R94: a remark on algorithm AS 181: The W test for normality. Applied Statistics 44, 547-551.

Shklovski, I., 2007. Residential mobility, technology \& social ties. Carnegie Mellon University, Human-Computer Interaction Institute Dissertation.

Simmel, G., 1999 [1908]. Le croisement des cercles sociaux. In: Sociologie, Etude sur les formes de la socialisation. PUF, Paris, pp. 407-452.

Teller, J., 2009. Development of communal areas in residential suburban neighbourhoods. Déviance et société 33, 547-556.

Urry, J., 2003. Social networks, travel and talk. British Journal of Sociology 54 $155-175$.

Urry, J., 2007a. Mobilities. Polity, Cambridge, UK.

Urry, J., 2007b. Des inégalités sociales au capital en réseau. Swiss Journal of Sociology 33, 9-26.

Wellman, B., Leighton, B., 1979. Networks, neighborhoods and communities. Urban Affairs Quarterly 14, 363-390.

Wellman, B., 1985. Domestic work, paid work and network. In: Duck, S., Perlman, D. (Eds.), Understanding personal relationships. Sage, London, pp. 159191.

Wellman, B., Carrington, P.J., Hall, A., 1988. Networks as personal communities. In: Wellman, B., Berkowitz, S.D. (Eds.), Social Structures: A Network Analysis. Cambridge University Press, Cambridge, UK.

Wellman, B., 1990. The place of kinfolk in personal community networks. Journal of Marriage and the Family 15, 195-228.

Wellman, B., 1996. Are personal communities local? Social Networks 18, 347-354.

Wellman, B., 1999. Networks in the Global Village. Westview Press, Boulder.

Wellman, B., Wortley, S., 1990. Different strokes from different folks. American Journal of Sociology 96, 558-588.

Wellman, B., Wellman, B., 1992. Domestic affairs and network relations. Journal of Social and Personal Relationships 9, 385-409. 
Wellman, B., Frank, K., 2000. Network capital in a multi-level world. In: Lin, N., Cook, K., Burt, R. (Eds.), Social Capital: Theory and Research. Aldine DeGruyter, Hawthorne, NY, pp. 233-273.

Wellman, B., 2001. Physical place and cyber place: the rise of networked individualism. International Journal of Urban and Regional Research 25, 227-252.

Wellman, B., 2002. The intersection of transportation networks, communication networks, and community networks. In: Black, W.R., Nijkamp, P.
(Eds.), Social Change and Sustainable Transport. Indiana University Press, Bloomington.

Wittel, A., 2001. Toward a network sociality. Theory, Culture and Society 18, 51 76.

Widmer, E.D., 2006. Who are my family members? Bridging and binding social capital in family configurations. Journal of Personal and Social Relationships 23 , 979-998. 